\title{
Making Action Easier: Behavioral Economics and Nudges for Extension Professionals ${ }^{1}$
}

\author{
Laura Warner, Kathryn Stofer, and Hayk Khachatryan²
}

As Extension turns more to effecting behavior change beyond simply raising awareness or understanding concerns, how do we not only help clientele make a change, but make it easier? Behavioral economics principles can improve the way we present options to clients, increasing the likelihood of them choosing desirable behaviors. This document offers an introduction to these concepts as well as practical strategies for setting the environment for change.

\section{Introduction to Behavioral Economics}

Have you ever tipped a restaurant server more than you normally would because the default on the payment kiosk was set to $25 \%$ ? Or, perhaps you held on to a monthly subscription service (for example, exotic teas or pet toys) longer than you wanted because you had to call customer service to cancel, whereas you signed up using a very simple online form. Would knowing that your neighbors spend less on their monthly water usage or electricity bill make you readjust your irrigation controller or thermostat? These are some examples of behavioral economics-based strategies, and while they often are used to increase the bottom line for someone financially, we can use the principles of this approach to better serve Extension clientele.

People tend to do the thing that is easiest, provides immediate (as opposed to delayed) payoffs, or has the fewest barriers (importantly, this can be doing nothing at all; Lee \& Kotler, 2011; McKenzie-Mohr, Lee, Schultz, \& Kotler, 2012). Following this principle, an Extension professional would probably have a bigger newsletter distribution list if, during program registration, attendees were automatically signed up for a newsletter with an option to opt out, rather than if they were invited to opt in to receiving a newsletter. This concept is derived from social marketing, an approach to behavior change that is being welcomed into Extension programming because of its ability to make programs more impactful and relevant.

Behavioral economics, a science of human decision-making that draws from theories of economics and social psychology, is a natural partner to social marketing. Principles of behavioral economics include the following (Executive Office of the President, 2016; Rothschild, 2001):

- There is a cost associated with making any behavior change, whether the individual is adopting, changing, or stopping something.

- Very small barriers to program access can make the difference in whether it is successful or not.

- People tend to discount the benefits of adopting a behavior when there is a delay in receiving the reward.

- There are typically many competing choices.

1. This document is AEC680, one of a series of the Department of Agricultural Education and Communication, UF/IFAS Extension. Original publication date October 2019. Visit the EDIS website at https://edis.ifas.ufl.edu for the currently supported version of this publication.

2. Laura Warner, associate professor; Kathryn Stofer, research assistant professor, Department of Agricultural Education and Communication; and Hayk Khachatryan, associate professor and Extension economist, Food and Resource Economics Department, UF/IFAS Mid-Florida Research and Education Center; UF/IFAS Extension, Gainesville, FL 32611.

The Institute of Food and Agricultural Sciences (IFAS) is an Equal Opportunity Institution authorized to provide research, educational information and other services

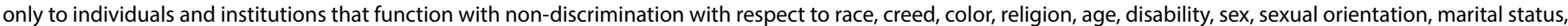

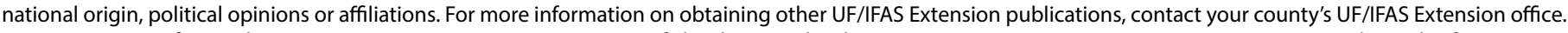
U.S. Department of Agriculture, UF/IFAS Extension Service, University of Florida, IFAS, Florida A \& M University Cooperative Extension Program, and Boards of County Commissioners Cooperating. Nick T. Place, dean for UF/IFAS Extension. 
- The resources needed to change behaviors (e.g., money, energy, time, health) are not unlimited.

Choice architecture is a behavior-change tool employed by behavioral economists. Choice architecture refers to intentionally changing a decision-making environment (such as the presentation, timing, or context) to influence a decision (Williamson, 2018). A specific type of choice architecture is known as nudging. Nudging is the act of subtly modifying the environments within which voluntary decisions are made without actually restricting any options (Ferraro, Messer, \& Wu, 2017; Ly, Mazar, Zhao, \& Soman, 2013). Classic examples of nudging are when healthier food is positioned to be easily accessible (e.g., displayed at eye level) to consumers in the line at cafeterias or when water options are displayed first before consumers can reach sugary drinks. In the context of Extension, Extension professionals may find nudges can improve clients' decision-making so they can solve problems in their lives.

Behavioral economics have been used in health and personal finance sectors but have been underused by those working in environmental contexts, especially water issues (Ferraro et al., 2017; Rothschild, 2001). We feel there are unlimited opportunities to integrate behavioral economics, specifically nudges, into Extension programs in the environmental sector and beyond.

Countries, including the United Kingdom and the United States, have adopted policies that include nudges to help people adopt positive behaviors (Bernedo et al., 2014; Executive Office of the President, 2016; Merritt, 2010). In 2015, the US government began using behavioral economics to serve Americans. For example, instead of requiring service members to have to take action to enroll in a savings plan, the US Department of Defense began requiring service members to actively indicate yes or no to enrolling in the plan (Executive Office of the President, 2016).

The first month of this trial resulted in almost 5,000 new enrollments and more than $\$ 1$ million in additional savings. (Visit https://sbst.gov for some other great examples.) Arranging healthier foods at the front of a school lunch line to encourage consumption is also a nudge.

\section{Benefits of Applying Nudges to Extension}

Extension professionals may appreciate the many benefits of using nudges:

- They are subtle changes that are typically simple to integrate into a program while being cost effective and easy to test (Ferraro et al., 2017; Merritt, 2010).

- Nudges "could lead to significant increases in participation or effort, making the programs highly cost-effective and desirable to policy-makers" (Ferraro et al., 2017, p. 4) at a relatively low cost.

- Nudges can have a "surprisingly persistent effect" (Bernedo, Ferraro, \& Price, 2014, p. 437) on behaviors.

- Nudges can be evaluated on small scales before they are rolled into larger Extension programs.

- Nudges can create momentum-they can be used to promote small changes that lead clientele to make bigger changes in the future (Williamson, 2018).

\section{A Few Important Concepts of Nudging}

Nudges can integrate the concept of active choice. Presenting people with an active choice means they are asked whether they want Option A or Option B. This concept is in contrast to a default option if a person doesn't take a particular action, including opting out.

Nudges can integrate normative messages. For example, when communicating with people who have not adopted the desired target behavior, messages might be used to inform clientele about the number of people in a certain sociodemographic group or geographic area (e.g., neighborhood, county) who have adopted the behavior (Ferraro et al., 2017). This approach is most likely to be effective when the target audience is underperforming in relation to the reference group and also wants to be like the reference group.

\section{Recommendations Extension Professionals Can Use to Apply Nudges to Extension Programs}

- Learn about your Extension clients' decision-making pertaining to your topic area: What decisions do clientele make that can influence the problem at hand? Consider the timing and contexts within which they make 
decisions. How can you modify the choice environment to support positive decision-making?

- Consider integrating normative messages into the decision-making environment. Inform people of the norm-that is, the decisions others make in the same situation. The use of social comparisons (for example, $60 \%$ of your neighbors have signed up for a solar energy evaluation) can help people follow what others do. This approach should only be used when the norm is the desirable behavior and the target audience is engaged in a less desirable behavior.

- Develop strategies to reduce the amount of time between the desired choice and the reward, or develop alternate intermediate rewards. For example, Extension clientele might not immediately see the results of eating a set number of fruits and vegetables each day. You could develop a checklist, calendar system, or series of social media badges to help clientele celebrate their good choices.

- Identify opportunities to convert passive defaults to active choices. For example, you might typically invite Extension program participants to come up to the front of a room to sign up to receive a new resource you've described during a presentation, meaning participants would not receive the information by default. Instead, you might ask them to actively opt in to or out of receiving this resource when they complete the program registration before class or program evaluation afterwards.

- Revisit the slate of choices you provide. Could you offer multiple desirable choices instead of a single desirable versus the less desirable option? For example, as part of a postprogram evaluation you might ask program participants to pledge to do one of the following: 1) Calibrate their sprinklers, 2) share an EDIS publication about water conservation on their social media pages, 3 ) test their rain shutoff device to determine if it is working, or 4) invite a neighbor to the next landscape water conservation program.

\section{Conclusion}

Voluntary behavior change is an important outcome of both Extension programming and social marketing. Nudges are a type of choice architecture that help remove or mitigate barriers to action. The use of nudges can help reduce chances of selecting less desirable behaviors and help people make good choices with minimal cognitive effort. Nudges are relatively simple to integrate into Extension programs and may result in increased adoption of desirable behaviors.

\section{References}

Bernedo, M., Ferraro, P. J., \& Price, M. J. (2014). The persistent impacts of norm-based messaging and their implications for water conservation. Journal of Consumer Policy, 37(3), 437-452. doi:10.1007/s10603-014-9266-0

Executive Office of the President. (2016). Social and Behavioral Sciences Team 2016 Annual Report. Washington, D.C.: National Science and Technology Council. Retrieved from https://sbst.gov

Ferraro, P., Messer, K. D., \& Wu, S. (2017). Applying behavioral insights to improve water security. Choices, 32(4), 1-6. Retrieved from http://www.choicesmagazine. org/UserFiles/file/cmsarticle_602.pdf

Lee, N. R., \& Kotler, P. A. (2011) Social marketing: Influencing behavior for good (4th ed.). Thousand Oaks, CA: Sage Publications.

Ly, K., Mazar, N., Zhao, M., \& Soman, D. (2013) A Practitioner's Guide to Nudging. Rotman School of Management Working Paper No. 2609347. Toronto: University of Toronto. doi:10.2139/ssrn.2609347

McKenzie-Mohr, D., Lee, N. R., Schultz, P. W., \& Kotler, P. (2012). Social marketing to protect the environment. Thousand Oaks, CA: Sage Publications.

Merritt, R. (2010). Forget the stick; it's all about the carrot now. Social Marketing Quarterly, 16(4), 155-157. doi:10.108 $0 / 15245004.2010 .526860$

Rothschild, M. L. (2001). A few behavioral economics insights for social marketers. Social Marketing Quarterly, 7(3), 8-13. doi:10.1080/15245004.2001.9961157

Smith, B. (2011). Behavioral economics and social marketing: New allies in the war on absent behavior. Social Marketing Quarterly, 16(2), 137-141. doi:10.1080/15245001003796241

Williamson, K. (2018). On nudging: Behavior change is a journey, not just a destination. Retrieved from http://rare. org/story/on-nudging-behavior-change-is-a-journey-notjust-a-destination/ 